Supplement of The Cryosphere, 15, 485-500, 2021 https://doi.org/10.5194/tc-15-485-2021-supplement (C) Author(s) 2021. This work is distributed under the Creative Commons Attribution 4.0 License.

(c) (1)

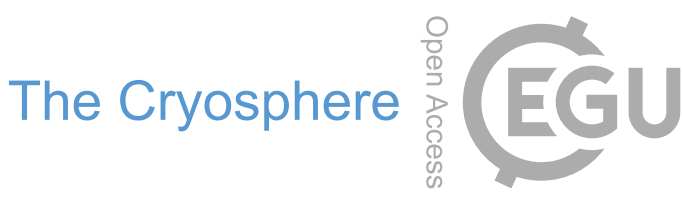

Supplement of

\title{
Thinning leads to calving-style changes at Bowdoin Glacier, Greenland
}

Eef C. H. van Dongen et al.

Correspondence to: Eef C. H. van Dongen (vandongen@vaw.baug.ethz.ch)

The copyright of individual parts of the supplement might differ from the CC BY 4.0 License. 

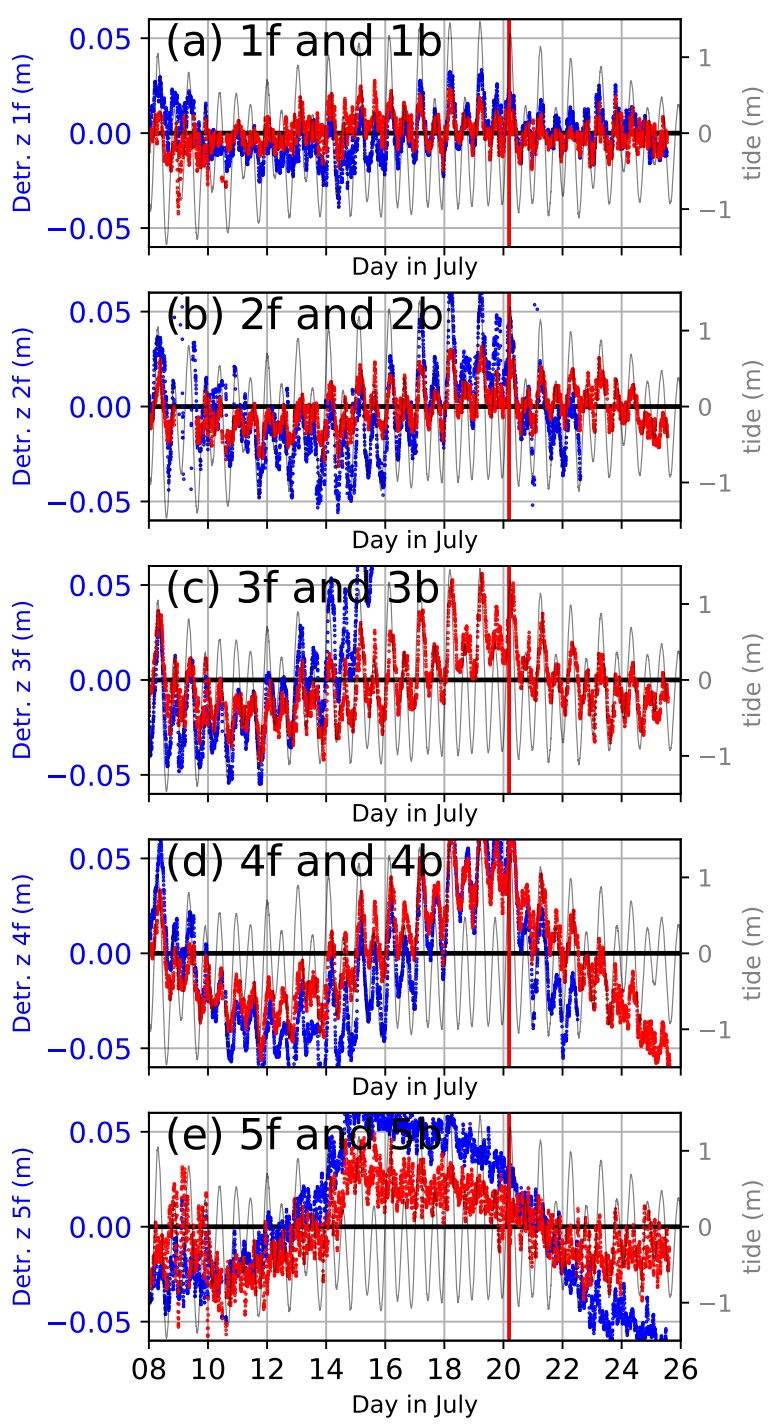

Figure S1. Detrended, $1 \mathrm{~h}$ moving average vertical position of GPS stations in 2019, with the tidal height in the background. The red vertical line indicates the timing of the large-scale calving event on 20 July. 
(a) $2015-05-0318: 30$

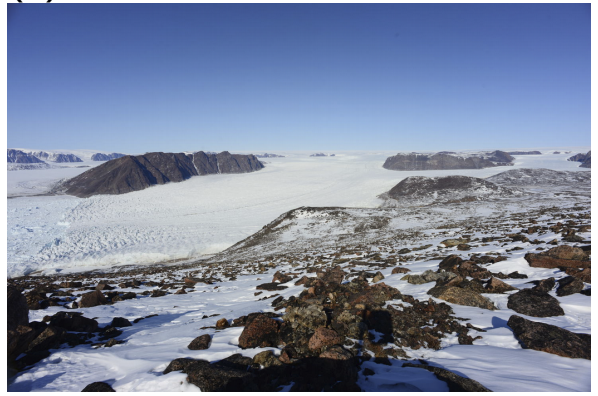

(c) 2015-07-27 20:30

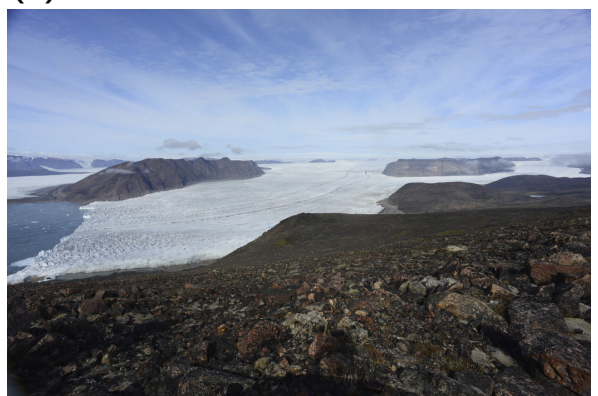

(e) 2016-06-17 21:00

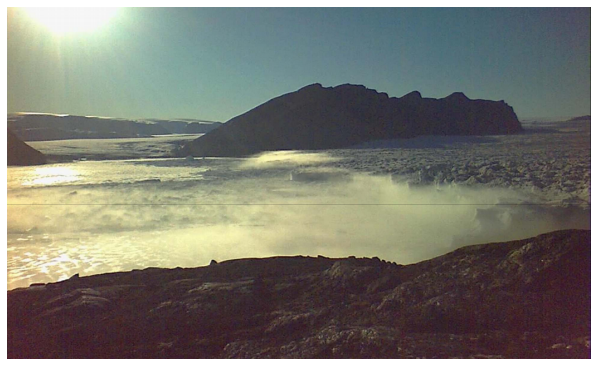

(g) 2017-07-07 21:00

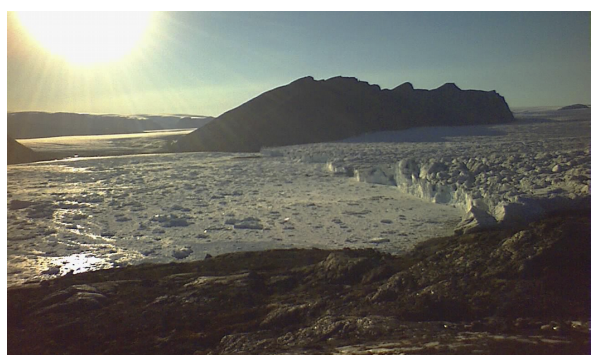

(b) $2015-05-0418: 30$

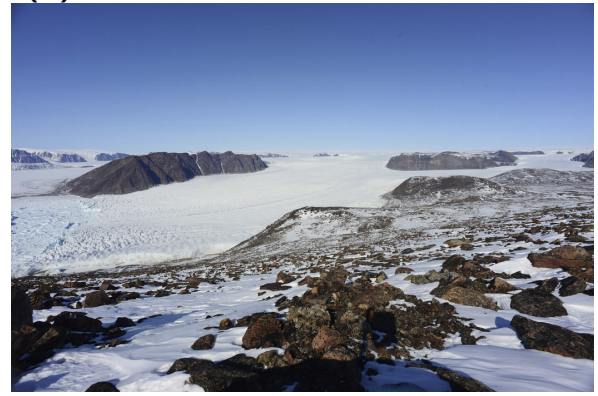

(d) $2015-07-28$ 20:30

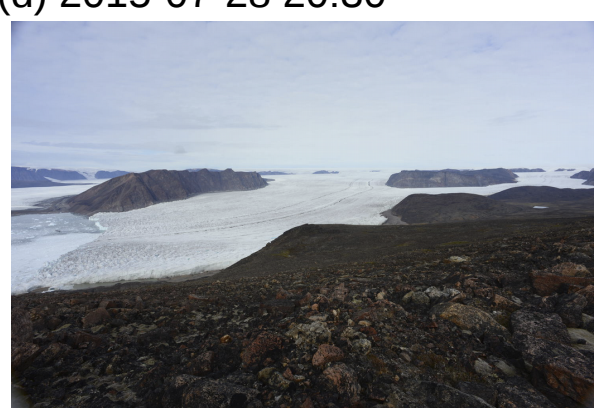

(f) 2016-06-18 00:00

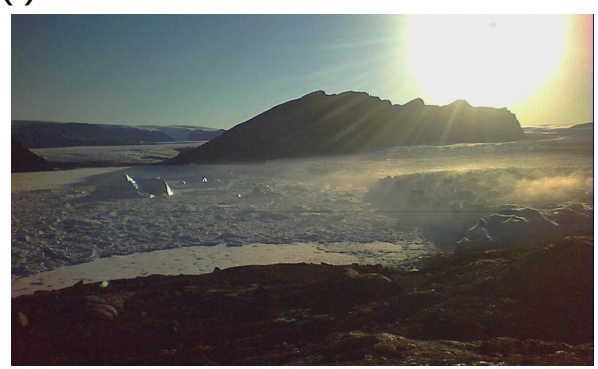

(h) 2017-07-08 00:00

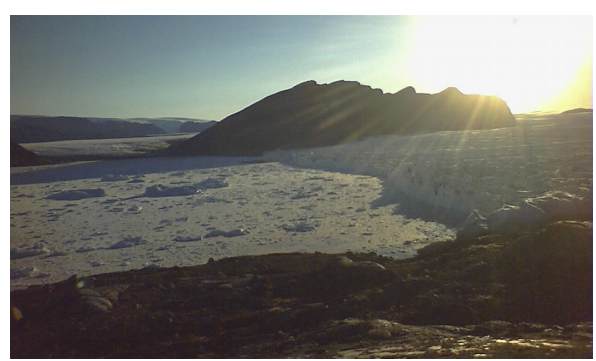

Figure S2. Timelapse imagery of major calving events prior to 2019. 


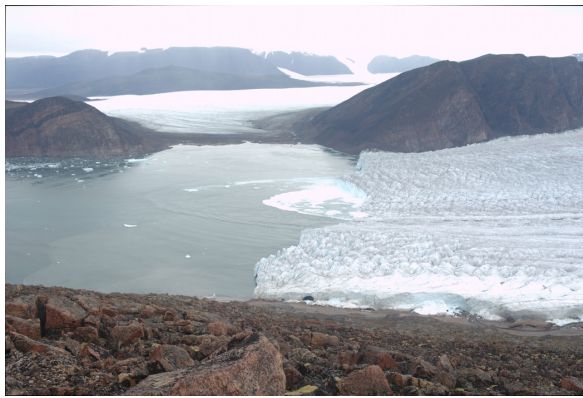

(a) $2019-07-20$ 04:00

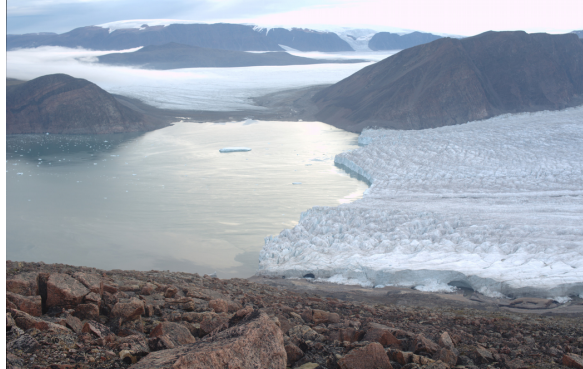

(c) $2019-07-2903: 00$

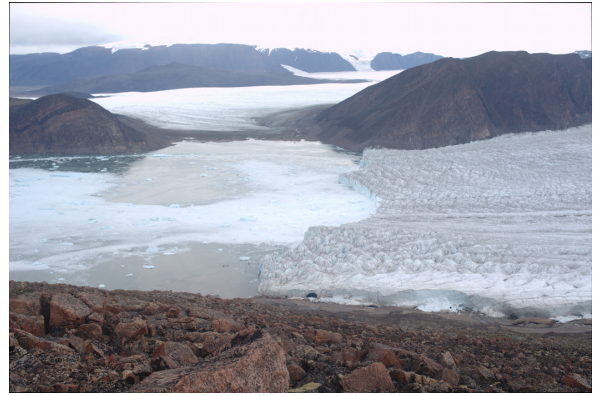

(b) $2019-07-20$ 05:00

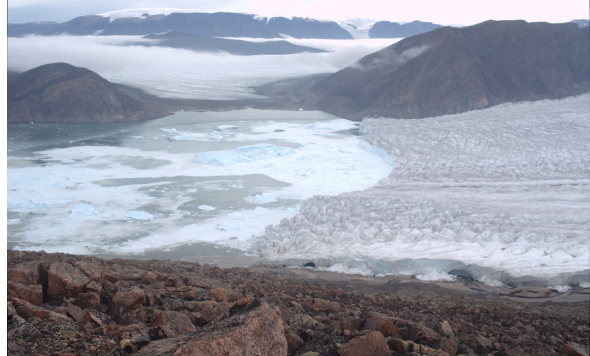

(d) 2019-07-29 04:00

Figure S3. Timelapse imagery of major calving events in 2019. 